\title{
LIDAR PROFILING IN THE LOWER TROPOSPHERE: EXPERIENCE FROM PECAN
}

\author{
Belay B. Demoz, Ruben Delgado, Brian Caroll, KeVIn Vermeesch \\ Joint Center for Earth Systems Technology, University of Maryland Baltimore County, Baltimore, MD 21250 USA \\ DAVID N. WHITEMAN \\ NASA/Goddard Space Flight Center, Greenbelt, MD 20771 USA
}

RICARDO SAKAI, SIUM TESFAY, LORENZA COOPER

Howard University, Washington, DC USA

\begin{abstract}
Results from the PECAN (Plains Elevated Convection at Night) campaign are discussed. In particular, the utility of simple backscatter lidars/ceilometers in quantifying atmospheric dynamics parameters and variables as well as evolution of the lower tropospheric dynamics are made. Cases of bore wave dynamics and the potential of these events in lofting of low level, moist, airmass and its consequence in thunderstorm initiation are made. A suite of thermodynamic profiling instruments are combined and compared to describe and visualize lower tropospheric dynamic evolution.
\end{abstract}

\section{Introduction}

PECAN (Plains Elevated Convection at Night) campaign, designed to advance the understanding of "continental, nocturnal, warmseason precipitation" in the Southern Great Plains, brought together a suite of remote sensing and in-situ instruments. Although PECAN's focus was on nocturnal convection during stable boundary layer (SBL) conditions with large CAPE (Convectively Available Potential Energy) located above the SBL and when nocturnal low-level jets (NLLJ) are present, it offered a good opportunity for intercomparison of lidar-radar-microwave and other profilers and assessment of their utility in atmospheric dynamics studies. PECAN's focus in these conditions stems from the fact that in this region thunderstorms are most common after sunset, and much of the heavier precipitation resulting from a variety of mesoscale convective systems (MCSs) tends to be correlated with the intensity of the NLLJ (e.g., Arritt et al. 1997; Tuttle and Davis 2006). An accurate prediction and an in-depth understanding of nocturnal convection in this region are lacking. In particular, the SBL structure leading to the initiation of nocturnal elevated convection $(\sim 900-600 \mathrm{hPa})$ is poorly understood and not well observed (e.g., Wilson and Roberts 2006). Operational observation of the thermodynamics of this atmospheric region is then better done with profilers - lidar being among the primary instruments.

Several Fixed PECAN (FP) Sites were deployed during the experiment. We report on data from a single site in Greensburg, Kansas, referred to as Fixed PECAN site \#2 (FP2). FP2 served as a hub for Profiling Microwave Radiometers, wind and water vapor lidars, radio sounding unit, a surface station, and a network of ceilometers. FP2 anchored the southwest part of the instrumentation for the PECAN domain. The instrumentation was organized by teams from Howard University, NASA/GSFC and UMBC as well as other collaborators. In addition, the Naval Postgraduate School (NPS), located in Monterey, CA, also deployed a $16 \mathrm{~m}$ main tower, a $6 \mathrm{~m}$ and $3 \mathrm{~m}$ supporting towers, a SODAR, a tethered balloon, and ceilometers. Moreover, NOAA/NSSL deployed an AERI system for part of the experiment.

We will discuss lidar and collaborating data from selected cases and demonstrate the utility of even the less sophisticated ceilometer-lidar in investigating storm and atmospheric dynamics. 


\section{Undular Bore: 3 June 2015}
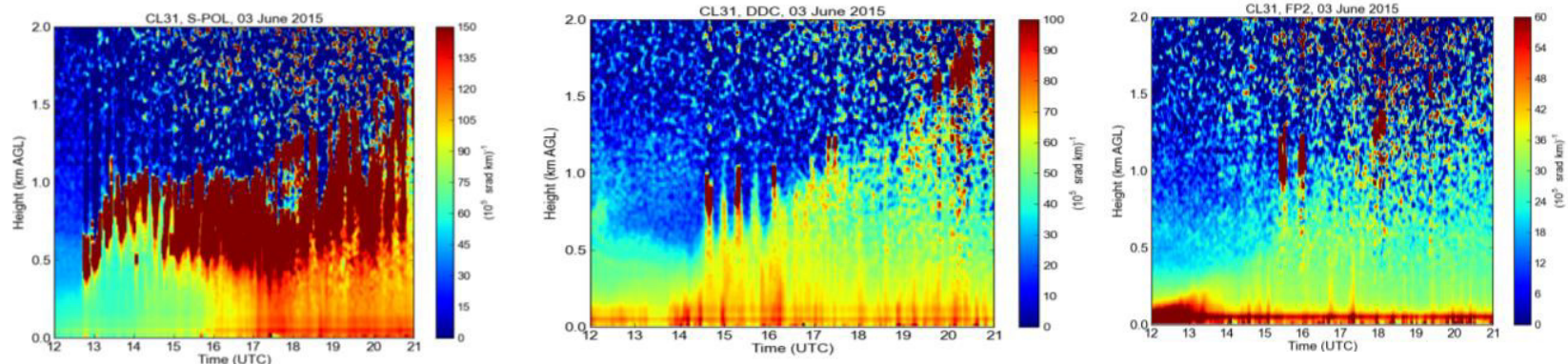

Figure 1: A plot of the aerosol backscatter profile obtained over three different sites by Vaisala CL31 ceilometer during the June 3, 2015 PECAN case over southwest Kansas, KS.

A wave train of roll clouds was visible early morning covering the entire southwest Kansas using satellite and visual (photos) observations (not shown). These waves resemble the classic bore-soliton conditions described by Christie (1989). The water vapor density, temperature and relative humidity at FP2 as well as aerosol backscatter signatures from three of the PECAN network sites (located at the central radar location SPOL, Dodge city, Kansas, and FP2) for this case are shown in fig. 1 above. The figures show the following wave characteristics (i) a progressively decaying wave pattern, undulations barely visible over the FP2 site but a strong cloud signature; (ii) about 100 minutes difference between the passage of the wave at the SPOL site and Dodge City, Kansas with additional 40min delay before reaching FP2; and (iii) the lift associated with the first cloud was higher at FP2 than the other sites despite the fact that the wave undulations were decreasing and dying; an indication of the role played by the evolving early morning boundary layer. In these plots, note that the backscatter false color depictions shown are relative and that scaling of individual profiles should not be compared. Although the manufacturer of these ceilometers has a calibration technique that attempts to correct and quantify the profiles and provide outputs in Str-1 per $\mathrm{km}^{-1}$, we have not found an independent confirmation of the validity of this calibration. There are however independent comparison experiments of one or more manufacturers of such lidars and we hope results will be published soon discussing the quantitative value of the profilers. This doesn't
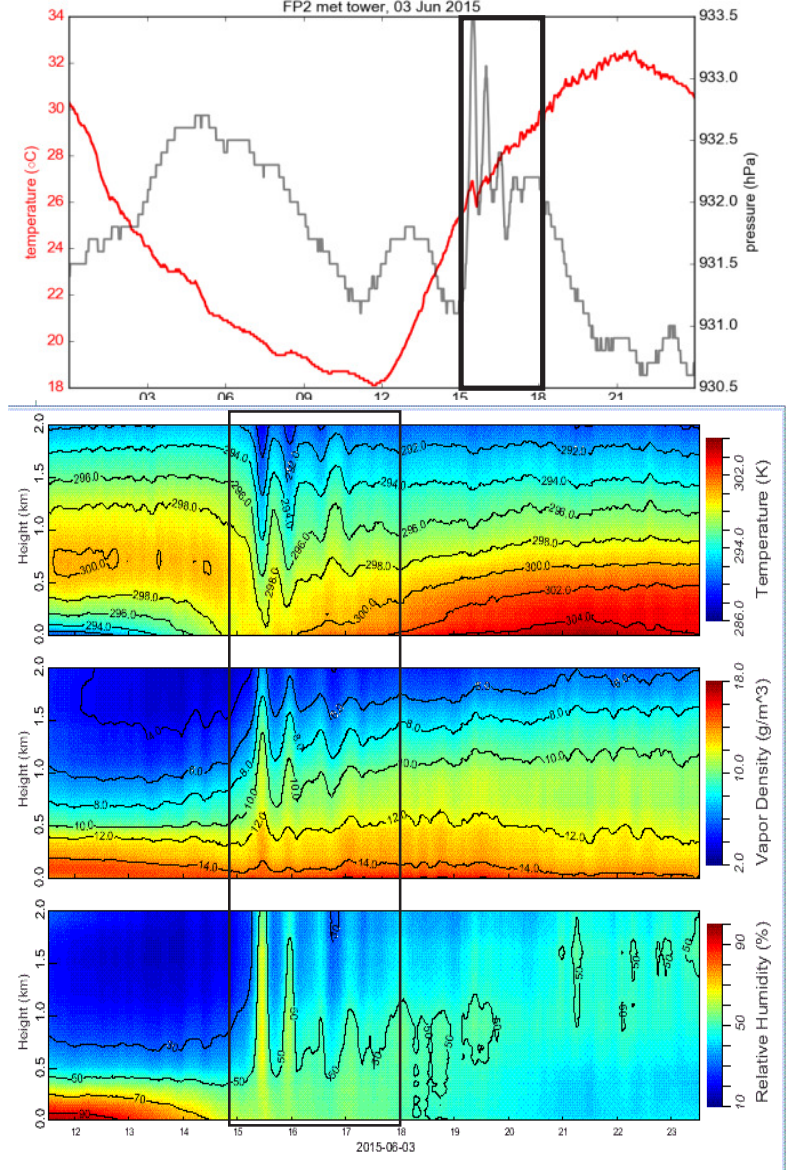

Figure-2: (A) Surface temperature and pressure at FP2 on 3 June 2015. Corresponding profiles of microwave measured Temperature, vapor density, and relative humidity are also shown. Passage time of the bore wave is indicated by blackbox on the plots.

diminish the value of the relative measurements in the study of atmospheric dynamics, as being attempted in this work.

In figure-2, we present a detailed look at the undulations captured by the CL31 lidar at FP2 (the weakest aerosol signature of the three 
sites in fig.1) and the resulting thermodynamic signatures as captured by surface meteorological stations and captured by the microwave radiometric profilers. Shown in fig. 2 are plots for the water vapor density $\left(\mathrm{g} / \mathrm{m}^{3}\right)$, Temperature $(\mathrm{K})$ and relative Humidity $(\%)$. Note that the seemingly weak perturbations captured by a simple ceilometer are an indication of intense water vapor and temperature modulations caused by the strong atmospheric dynamics of the bore/soliton on this day. This moisturetemperature distribution is key to understanding storm initiation and moistening of the upper tropospheric region. The pressure perturbations and subsequent atmospheric oscillations in temperature, moisture and aerosol backscatter profiles in this case reveal the entire sub-cloud layer. Surface signatures also are clearly revealed in the pressuretemperature perturbations and thus the dynamics has a clear surface signal and are hence not of an "elevated" nature. This is not always true - there are cases where the strong dynamic oscillations in the thermodynamic profiles are less evident or "weak at best" in the surface signal.

Such an example is a case of an undular bore that occurred on 14 July 2015. On this date, shown in Fig. 3, the wave oscillation occurred at night where there was no developing boundary layer. This case also had two periods of pressure jumps, at 5:30UTC and 7:00 UTC. The magnitudes of the pressure jumps recorded were similar but the resulting atmospheric water vapor perturbation was very different. As can be seen from figure 3, the low level (below $1 \mathrm{~km}$ ) water vapor mixing ratio and temperature did not show that strong perturbations, but the upper level $2-3 \mathrm{~km}$ water vapor wave reveal a strong dynamics. This case revealed a very strong and persistent lofting of the warm-moist near-surface airmass up to almost $3 \mathrm{~km}$ in elevation. This lifting of the moist layer was much larger than the previous case discussed $(\sim 0.5 \mathrm{~km})$.

These two cases did not initiate a lasting convection, a subject of PECAN, but fall in the continuum of bore-wave dynamics that were observed. During PECAN a case was observed (not shown here) that was likely part of a bore- wave system that initiated severe convection. A detailed presentation of these two cases and the additional case that may have triggered an intense convection during PECAN will be discussed.
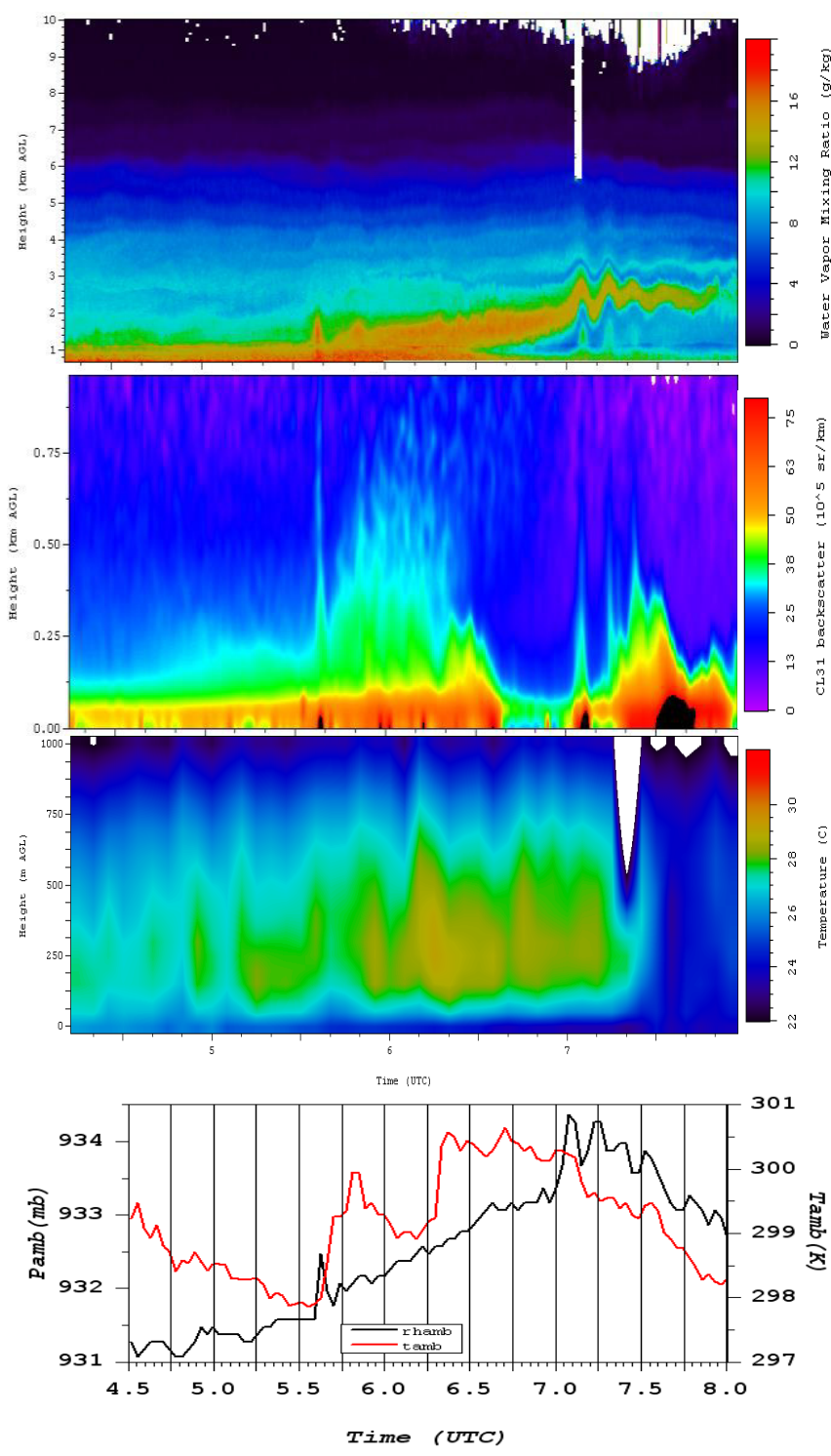

Figure-3: Profiles of (A) water vapor mixing ratio measured by the NASA/GSFC ALVICE Raman lidar (B) Vaisala CL31ceilometer measured backscatter (C) Temperature profile measured by the MTP and (D) Surface temperature and Pressure made at FP2 on 14 July 2015.

In addition to the discussion above and a description of the PECAN ceilometer network design, a progress report on the NOAA-NWS effort to create a national network of ceilometers from the Automated Surface 
Observing System (ASOS) network (which consists of close to 1000 lidar-ceilometers nationwide) will be presented and reported.

\section{LLJ}

An additional objective of the PECAN experiment was investigation of the character and evolution of the plains low-level jet (LLJ). The LLJ is defined simply as lowertropospheric maximum in the vertical profile of the horizontal wind, and occurring in the boundary layer at night. Of practical interest is their impact on the transport of moisture although it should be noted that a theoretical framework explaining them is still not quite settled yet (Du and Rottuno, 2014; Shapiro et al. 2016). Notable is the large amount of vertical wind shear associated with LLJ and the observation that they are typically supergeostrophic by a large (>50\%) amount with no appreciable vertical wind. There are a number of specific geographic locations that have been identified as especially favourable for LLJ development and their impact. The Southern Great Plains (SGP) region of the United States is one such region where the LLJ events have been studied extensively because of their impact on the development of nocturnal severe storms and their role in precipitation (Tollerud et al., 2004, Geerts et al. 2016).

During PECAN, several cases of LLJ were observed at FP2 and the distributed network stations. A summary of findings and progress in analysis to date of lidar observations made will be made.

\section{Conclusions}

A summary of FP2 measurements and lidar instrumentation during the PECAN experiment is discussed. Utility of simple backscatter lidars, CL31 Vaisala ceilometer, were used to diagnose lower atmosphere dynamics. In particular, the pressure perturbations that would result in water vapor lofting and thus may lead to convection initiation and often referred to as bore-solitary waves are discussed. Detailed data from two case studies, including surface meteorology, colocated microwave radiometers, Raman and Doppler wind lidars are presented. Preliminary findings indicate that the ceilometer profile data is an excellent indicator of the tropospheric dynamics. When combined with surface meteorology data, these ceilometers could lead to a useful documentation and statistics of the occurrence of bore events. These PECAN data sets are being used as a demonstration project for the proposed NOAA/NWS - ASOS ceilometer network. A detailed discussion and report of these and related activity will be presented at the meeting.

\section{Acknowledgement}

This research was supported in part by NSF (Award Number 1503563) and NASA Earth Science Directorate's weather research Program under the direction of Dr. Jack Kaye.

\section{References}

Geerts, B., et al., 2016: The 2015 Plains Elevated Convection At Night (PECAN) field project. Bull. Amer. Meteor. Soc. doi:10.1175/BAMSD-15-00257

Tollerud et al., 2004: Multiscale analyses of moisture transport by the central plains lowlevel jet during IHOP. 20th Conf. On Weather Analysis and Forecasting, Seattle, WA, Amer. Meteor. Soc., CD-ROM, P4.21.

Shapiro, A., E. Fedorovich, and S. Rahimi, 2016: A unified theory for the Great Plains nocturnal low-level jet. J. Atmos. Sci., 73, 3037-3057.

Du Y., and R. Rotunno (2014): A simple analytical model of the nocturnal low-level jet over the Great Plains of the United States. J. Atmos. Sci., 71, 3674-3683.

Arritt, R. W., T. D. Rink, M. Segal, D. P. Todey, C. A. Clark, M. J. Mitchell, and K. M. Labas, 1997: The Great Plains Low-Level Jet during the Warm Season of 1993. Mon. Wea. Rev., 125, 2176-2192.

Tuttle, J. D., and C. A. Davis, 2006: Corridors of warm season precipitation in the central United States. Mon. Wea. Rev., 134, 2297-2317.

Wilson, J. W. and R. D. Roberts, 2006: Summary of convective storm initiation and evolution during IHOP: observational and modeling perspective. Mon. Wea. Rev.,134, 23-47.

Christie, D. R., 1989: Long nonlinear waves in the lower atmosphere. J. Atmos. Sci., 46, 14621491. 